\title{
DYNAMIC IDENTIFICATION OF DAMAGE IN BRICK MASONRY WALLS
}

\section{S. IVORRA ${ }^{1}$, D. BRU ${ }^{2}$, I. GISBERT ${ }^{3}$, FJ.. BAEZA ${ }^{4}$, B.TORRES ${ }^{5}$ D. CAMASSA $^{6}$}

\author{
${ }^{1}$ Department of Civil Engineering. Universidad de Alicante \\ Carretera San Vicente, S/N, 03690 San Vicente del Raspeig (Alicante), Spain \\ e-mail: sivorra@ua.es, web page: http://www.ua.es \\ ${ }^{2}$ Department of Civil Engineering. Universidad de Alicante \\ Carretera San Vicente, S/N, 03690 San Vicente del Raspeig (Alicante), Spain \\ e-mail: david.bru@ua.es, web page: http://www.ua.es \\ ${ }^{3}$ Department of Civil Engineering. Universidad de Alicante \\ Carretera San Vicente, S/N, 03690 San Vicente del Raspeig (Alicante), Spain \\ e-mail: ignacio.gisbert@ua.es, web page: http://www.ua.es \\ ${ }^{4}$ Department of Civil Engineering. Universidad de Alicante \\ Carretera San Vicente, S/N, 03690 San Vicente del Raspeig (Alicante), Spain \\ e-mail: fj.baeza@ua.es, web page: http://www.ua.es \\ ${ }^{5}$ Department of Civil Engineering. Universidad de Alicante \\ Carretera San Vicente, S/N, 03690 San Vicente del Raspeig (Alicante), Spain \\ e-mail: Benjamin.torres@ua.es, web page: http://www.ua.es \\ ${ }^{5}$ Department of Civil Engineering Sciences and Architecture. Politecnico di Bari \\ Via Re David, 70125 Bari, Italy \\ e-mail: domenico.camassa@poliba.it, web page: http://www.poliba.it
}

Keywords: OMA, Masonry, Monitoring, Non-Destructive Inspection

\begin{abstract}
This paper shows the experimental and numerical analysis developed on a brick masonry wall of $3 \times 2.5 \times 0.2 \mathrm{~m}$ to understand the changes on its dynamic behaviour with different stiffness situations: (i) original, (ii) loaded with different load levels, (iii) damaged by horizontal in plane loads, (iv) retrofitted with Textile Reinforced Mortars (TRM) and (v) retrofitted and damaged by horizontal in plane loads. This analysis has been developed at the Civil Engineering Lab at the University of Alicante. On this masonry wall a matrix of 8 seismic accelerometers have been installed to evaluate, in plane and out of plane, changes in the main frequencies, modal damping ratios and modal shapes. By the use of Operational Modal Analysis techniques the results shows that the changes on the stiffness have important influence on the main frequencies and in the modal damping ratios. Very low influence have been detected on the modal shapes due to the low level of external vibrations generated during the tests. Due to the low level of vibrations inside the lab, the classical
\end{abstract}


application of ambient vibrations for OMA has been not possible and an external white noise force has been introduced on the top the wall by the use of a shaker to generate a general level of vibrations on the specimen.

\section{INTRODUCTION}

Masonry walls are a traditional structural system used in many buildings, and it can be found today as the constructive solution for new buildings. However, these elements show a brittle behavior for in plane and out plane loads, especially for seismic or dynamic loads [1]. In particular, the more usual failure modes for in plane loads are toe crushing, rocking, diagonal cracking or sliding [2]. In case of out of plane loads, these elements shows a very slow bending strength. Different reinforcement techniques can be used to improve the in plane and out plane behavior of the masonry walls. Fiber reinforced polymers (FRP) has been used for different authors such as [3]. However, these solutions show problems related with the contact between them and the masonry. Other solution is the textile reinforced mortar (TRM) [4]. These materials show a better compatibility with masonry and avoid problems related to debonding or permeability issues.

The main objective of this research is the evaluation of the TRM reinforcement for dynamic loads. In particular, changes in the vibration frequencies, modal shapes, and damping factor [5] have been evaluated by means of OMA (Operational modal analysis), before and after the

\section{reinforcement process}

\section{MASONRY WALIS}

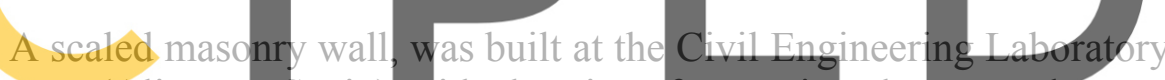

Alicante (Alicante, Spain) with the aim
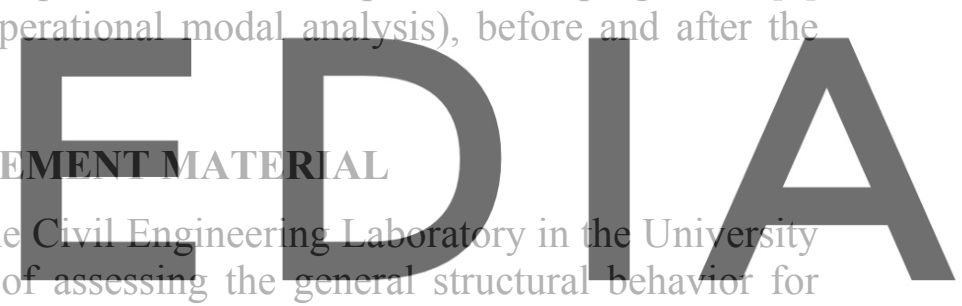

shear forces and dynamic loadas. In particular, the cracking pattern and the changes in

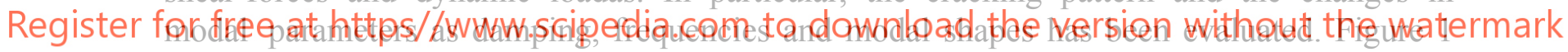
shows the general view of the building.

The masonry walls were constructed using clay bricks laid by means of $10 \mathrm{~mm}$ thick lime mortar joints adopting an English bond disposition. Table 1 shows the dimensions and compression strength of bricks and the mean compression strength of lime mortar at 28 days and 100 days (days in which tests, described later, were performed). The total dimensions of each wall is $3 \times 2.5 \times 0.2 \mathrm{~m}$.

Table 1. Geometric characteristics and compression strength of bricks and lime mortar.

\begin{tabular}{lccc} 
Bricks & \multicolumn{3}{c}{ Lime mortar } \\
\hline $\begin{array}{c}\text { Dimensions } \\
{[\mathrm{mm}]}\end{array}$ & $230 \times 110 \times 50$ & $\begin{array}{c}\text { Compression strength at } \\
28 \text { days [MPa] }\end{array}$ & 4.25 \\
& & Compression strength at & 5.98 \\
$\begin{array}{c}\text { Compression } \\
\text { strength }[\mathrm{MPa}]\end{array}$ & 13.99 & 100 days [MPa] & 5.98 \\
\hline
\end{tabular}


Foundations were prepared for constrain displacements with the use of steel plates and anchors to the main concrete slab of the laboratory, Figure 1. In addition, the building might have connected at the top of the lateral walls to a servo-hydraulic jack by means of a steel beam supported by props. Dimensions of the walls, its disposition and experimental set-up are shown in Figure 1. By the use of some steel elements the wall was preloaded with a compression load of $300 \mathrm{kN}$ to simulate the weight of the structural elements in a real situation. With this preload, to generate damage on the wall, a cyclic incremental pushover load the top of the wall to achieve the complete cross crack pattern due to shear forces.

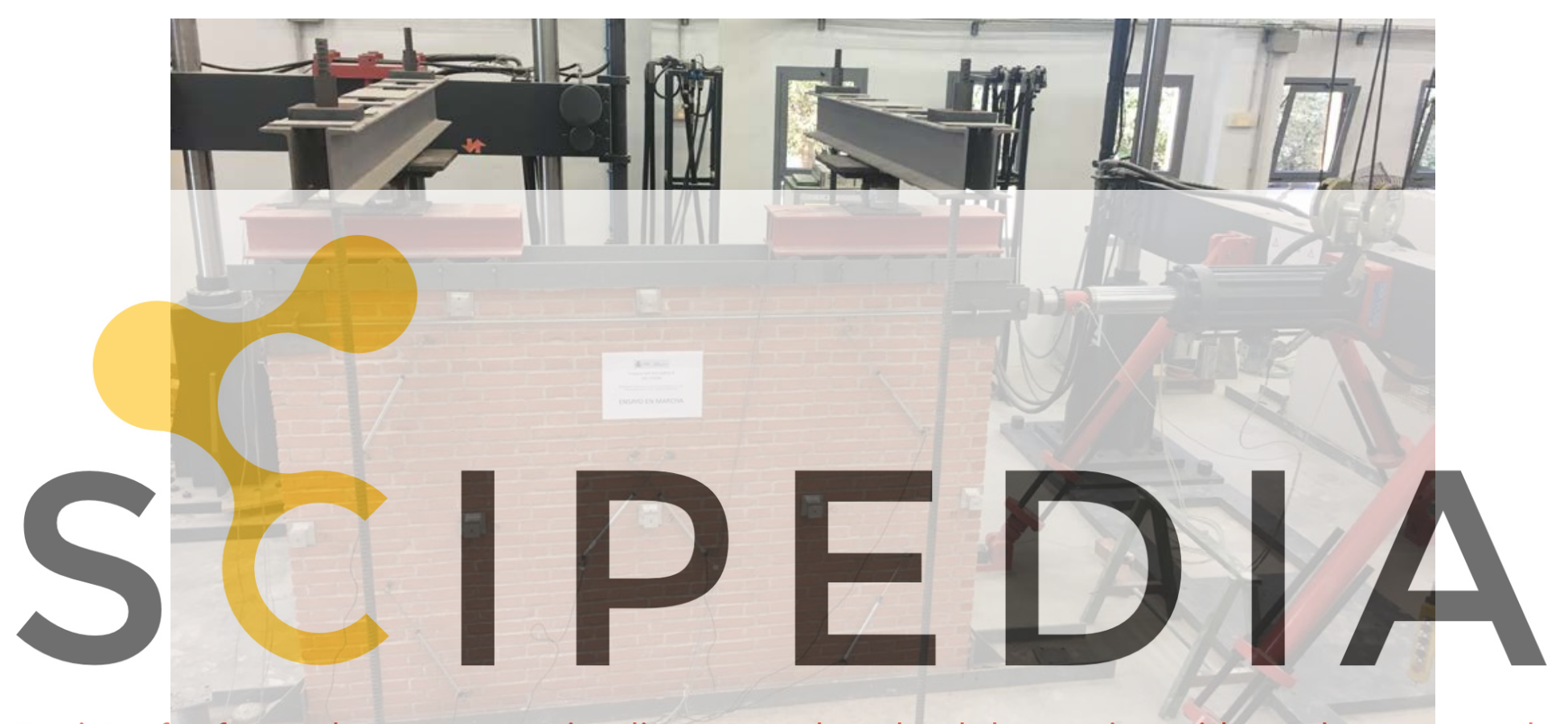

Register for free at https//www.scipedia.com to download the version without the watermark
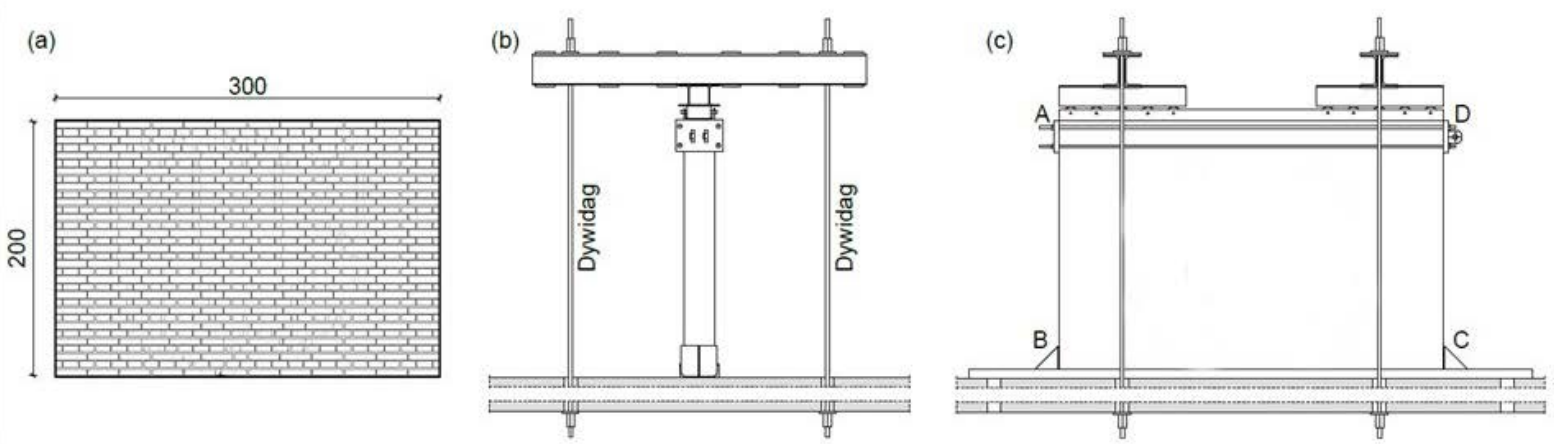

Figure 1. General view of sensors location, anchorage system, preload device and jack for the horizontal loads

Once the tests were performed, specimens have been reinforced with Textile Reinforced Mortar (TRM) materials. On the one hand, the cracks have been sealed with semiliquid mortars. On the other hand, the wall was reinforced with TRM with the aim of evaluating the efficacy of 
cementitious-based strengthening to: (i) improve the seismic behavior of masonry structures, and (ii) avoid a seismic-induced premature failure of poor-quality masonries. The adopted TRM retrofitting technique comprised a $25 \times 25 \mathrm{~mm}$ glass textile grid embedded into a $10 \mathrm{~mm}$ thick cementitious layer applied along the outer face of the overall building (Figure 2). Table 2 shows the mechanical properties of the reinforced material used in this research.

Table 2. Mechanical properties or reinforced materials.

Mortar

Textile mesh

\begin{tabular}{cccc}
\hline $\begin{array}{c}\text { Compression } \\
\text { strength at } 28 \\
\text { days }[\mathrm{MPa}]\end{array}$ & 15 & Tensile strength $[\mathrm{kN} / \mathrm{m}]$ & 45 \\
$\begin{array}{c}\text { Elastic modulus } \\
{[\mathrm{MPa}]}\end{array}$ & 8000 & Elastic modulus [MPa] & 72000 \\
\hline
\end{tabular}

When this kind of reinforcement is applied on damaged structures, it comprises different steps. Indeed, the masonry support was preliminarily treated injecting the wider cracks (Figure 2.a) to restore the original load bearing capacity of the damaged masonries. Then, a $5 \mathrm{~mm}$ thick cementitious layer was applied on the outer face of the walls (Figure 2.b). This layer is necessary to allow the bond between the masonry support and the glass textile grid (Figura 2.c). It is worth mentioning that, conversely to FRP composites, TRM materials allow to comply with the current requirements of compatibility and reversibility of the retrofitting with respect to brittle supports due to the presence of a mortar matrix instead of an epoxy one [6]. Finally,

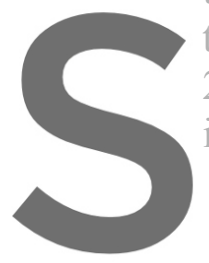
the glass grid was cover 2.d). The layers composing the TR in Figure 2.

Register for free at https//www.scipedia.com to download the version without the watermark
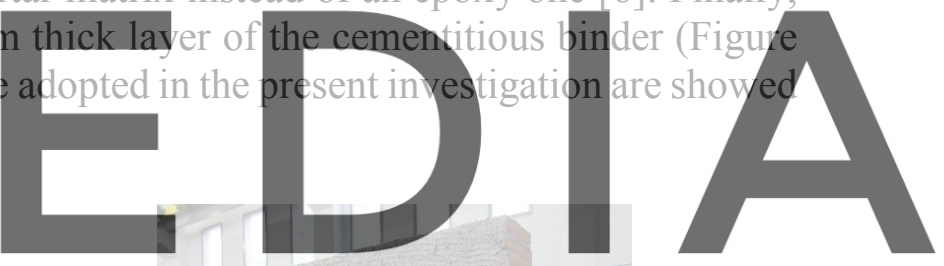

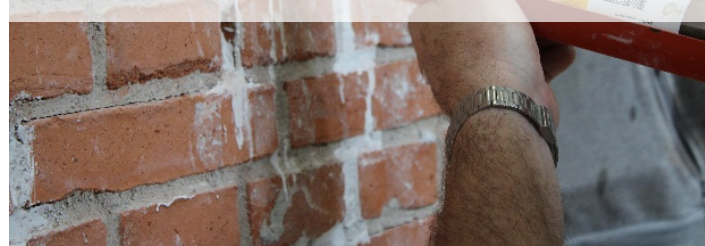

(a)

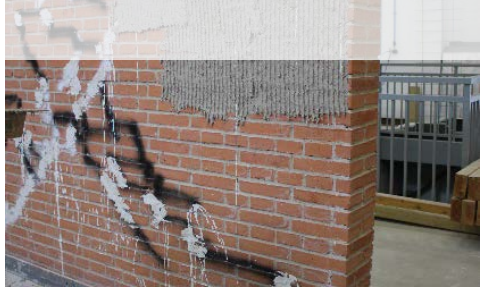

(b) 


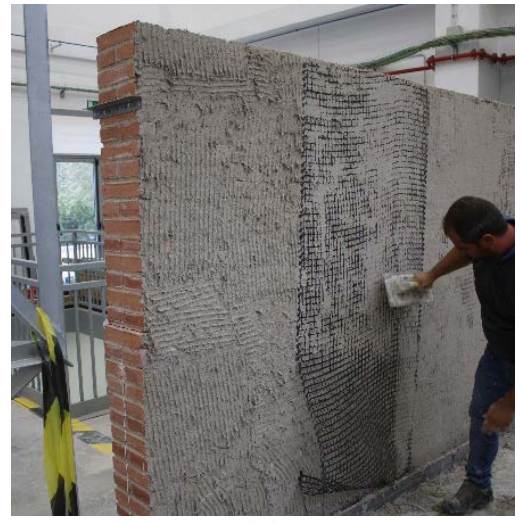

(c)

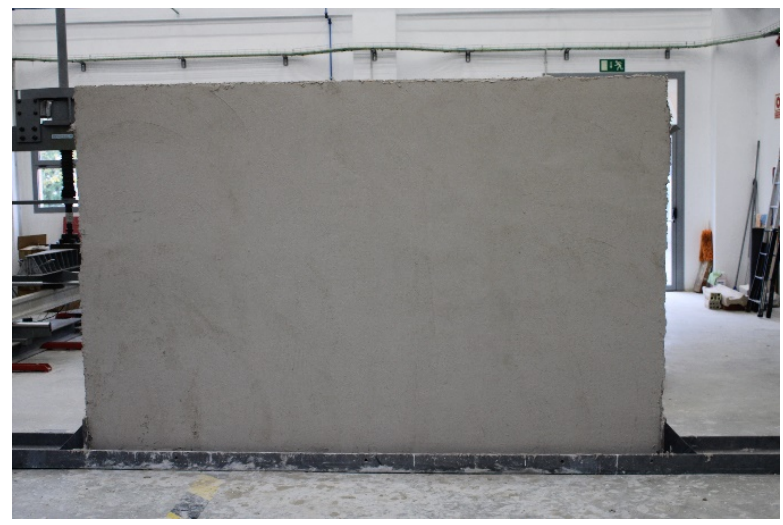

(d)

Figure 2. (a)- Injection the wider cracks. (b)- $5 \mathrm{~mm}$ thick cementitious laye applied on the outer face. (c)Application of the glass fiber mesh. (d)- Reinforced masonry wall.

\section{MONITORING AND DESCRIPTION OF THE MODAL ANALYSIS}

The methodology for dynamic identification has been divided in four phases: (i) Unreinforced pre-damage; (ii) Unreinforced post-damage; (iii) Reinforced pre-damage; (iv) Reinforced post-damaged. White noise vibrations has been registered during all phases with a sampling frequency of $2000 \mathrm{~Hz}$. Three records of $300 \mathrm{~s}$ have been done in each phase, and the

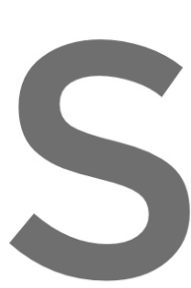
mean values have bee.

equal to $10 \mathrm{~V} / \mathrm{g}$ have b

been registered using

model PCB 482A22.

With the aim to $i$
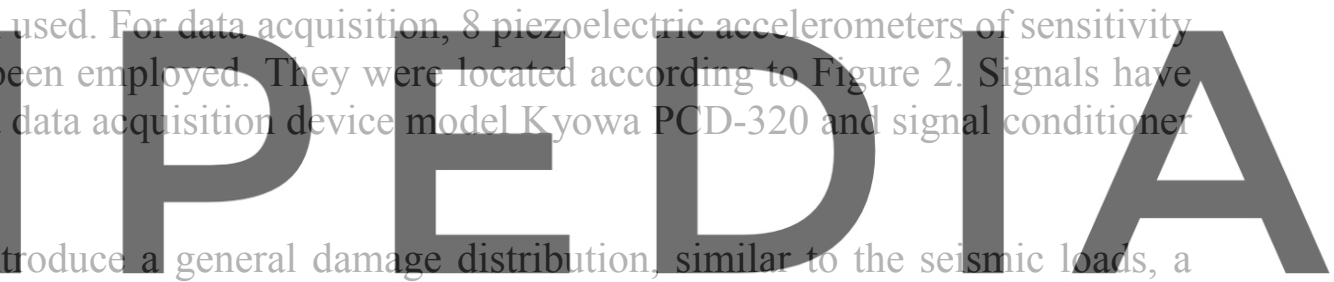

cyclic load with increasing amplitude of the displacement from $0.2 \mathrm{~mm}$ to $12 \mathrm{~mm}$ has been

Register fore jack with a displacement load control. In this paper the results showed are related with the initial phases previously to the damage and the final phases after the full damage procedure. It is important to note that the reinforced building is the unreinforced building repaired after all the damage phases.

Finally, Operational Modal Analysis (OMA) was used to analyze the vibration frequencies and the damping factor. The technique used is the Enhanced Frequency Domain Decomposition (EFDD), according to the Artemis software. 


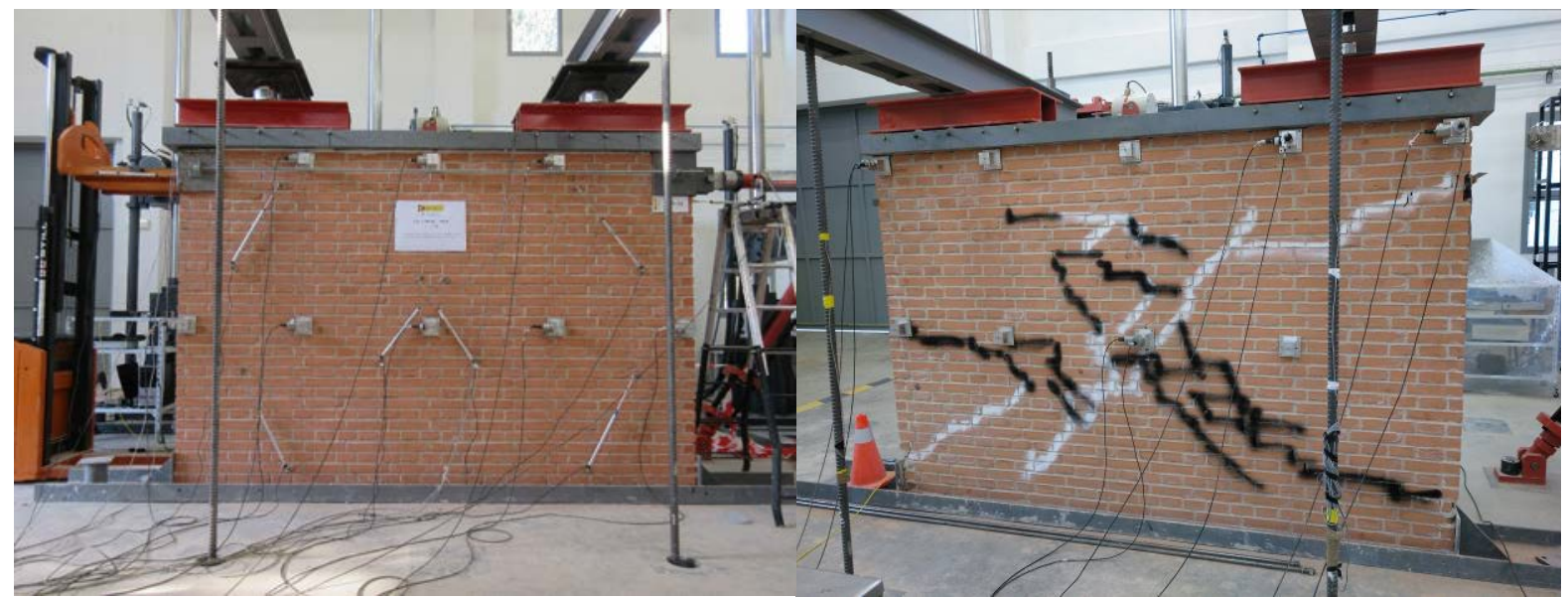

(a)

(b)

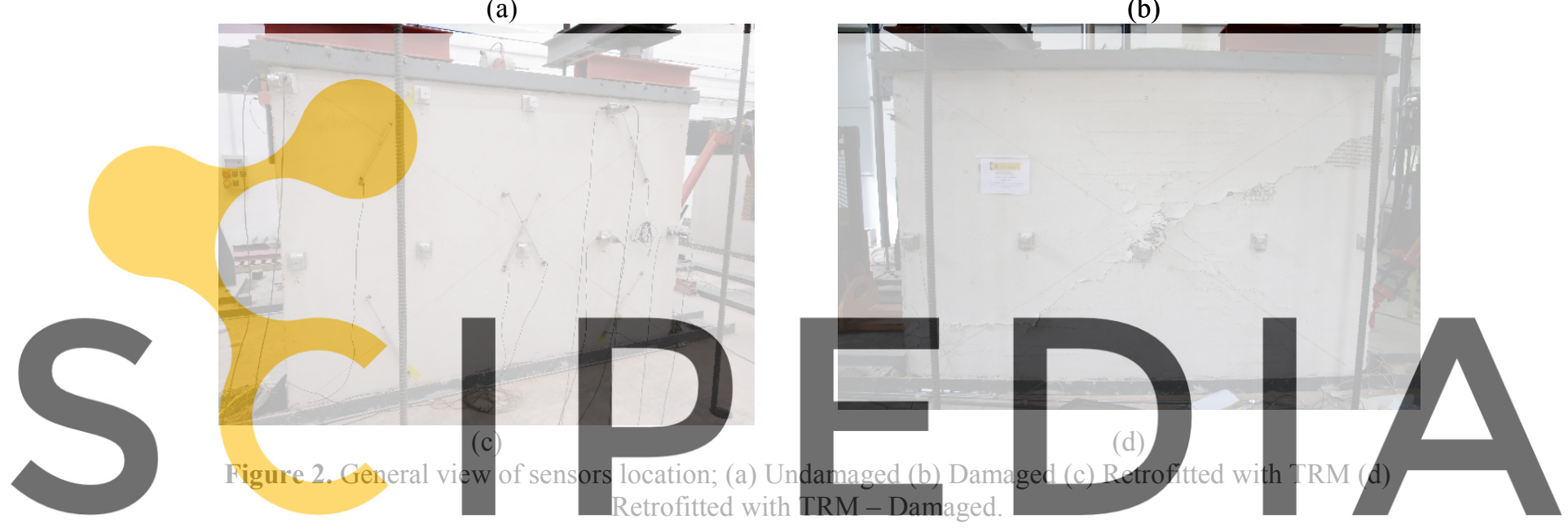

Register for $\underset{4}{\text { free at https//wW }}$, hww.scipedia.com to download the version without the watermark

In case of the unreinforced wall, a classical crack pattern (Figure 2) arose with increasing damage. In particular, a well-defined diagonal crack (white crack) and some diffused cracks (black cracks) appeared. As it can be seen in Figure 2, the cracks mainly follow mortar joints, except in some points where it cross one or more bricks.

Regarding operational modal analysis, the first three vibration modes have been identified. The Figure 3 shows a typical Singular Value Plot, in a value range from 0 to $50 \mathrm{~Hz}$, obtained through the EFDD technique. The estimated natural frequencies and damping ratios are shown in Table 3 and the mode shapes are represented in Figure 4. The first two vibration modes are out-of-plane modes, the third is an in-plane mode. For each identified vibration mode, the natural frequency decrease and the damping ratio increase due to damage. In particular, a reduction of natural frequency equal to $21.14 \%, 22.04 \%$ and $57.15 \%$ and an increase of damping ratio equal to $10.11 \%, 69.94 \%$ and $12.04 \%$ have been evaluated respectively for the first, the second and the third mode. Finally, in order to evaluate the changes in mode shapes due to damage, the Modal Assurance Criterion (MAC) has been used. 


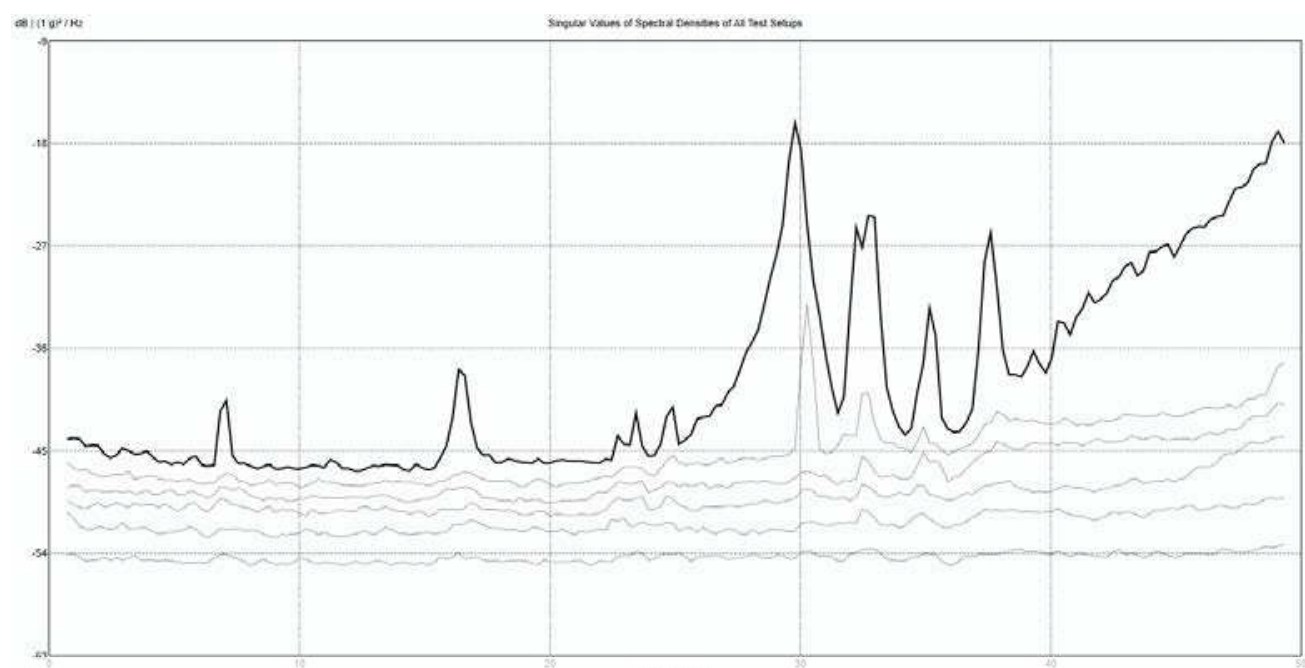

Figure 3. Typical Singular Value Plot obtained by processing acceleration data of the wall through the EFDD technique.

The reduction of natural frequency due to damage indicates a reduction of wall stiffness. Moreover, the increase of damping ratio suggests an increase of energy dissipation due to material friction along the cracks. It is worth noting that, since the greatest frequency reduction corresponds to the third mode, the damage has mainly affected the in-plane stiffness. Moreover,

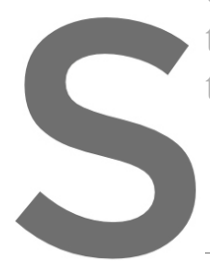

the MAC values reported in Tble 4 suggest that the damage nainly affects the rnode shape the second vibration node.

Table 3: Estimated natural frequencies and damp Pre-damage

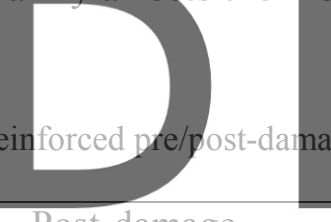

Post-damage

Frequency $(\mathrm{Hz})$
Register for free aț

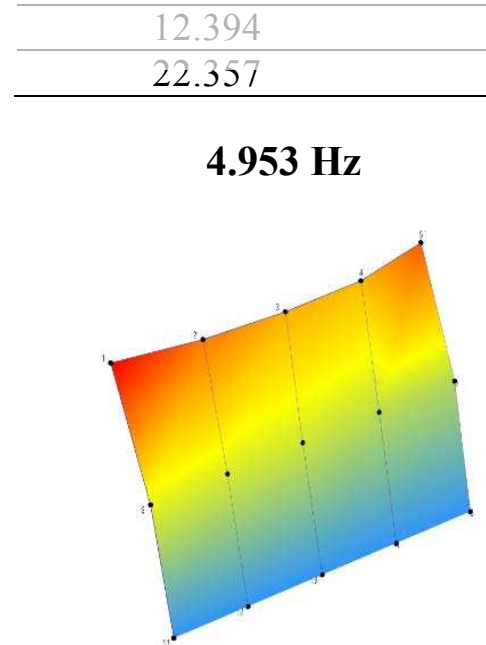

(a)
$12.394 \mathrm{~Hz}$

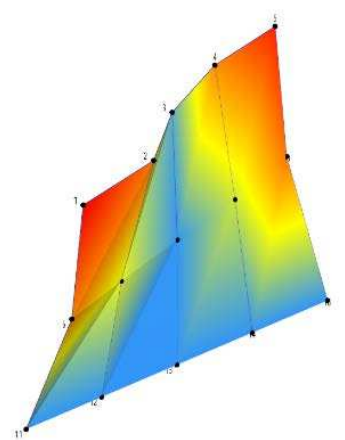

(b)
22.357 Hz

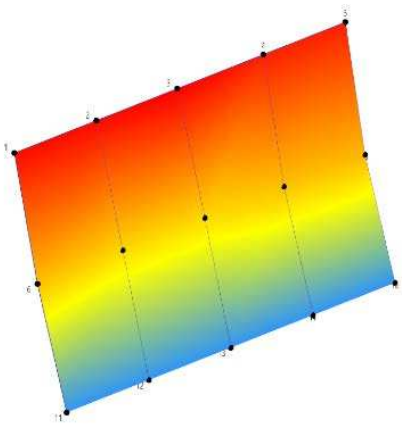

(c) 


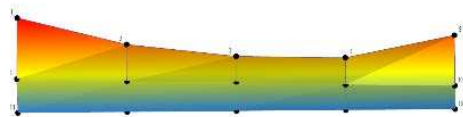

(d)

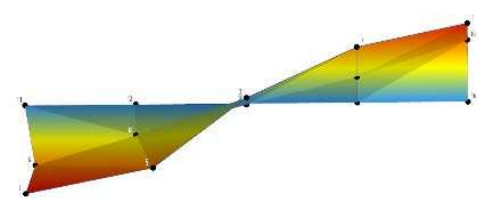

(e)

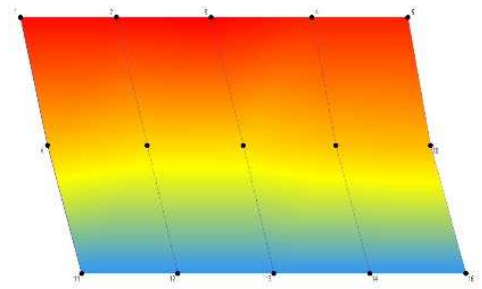

(f)

Figure 4. Frequencies and mode shapes for the unreinforced pre-damage wall. General view: (a), (b), (c), (d). Plan view: (e), (f), (g). Front view: (h).

Table 4: MAC values between unreinforced pre and post damage wall.

\begin{tabular}{cccc} 
Frequency $(\mathbf{H z})$ & $\mathbf{4 . 9 5 3}$ & $\mathbf{1 2 . 3 9 4}$ & $\mathbf{2 2 . 3 5 7}$ \\
\hline $\mathbf{3 . 9 0 6}$ & 0.891 & 0.022 & 0.039 \\
\hline $\mathbf{9 . 6 6 2}$ & 0.044 & 0.728 & 0.010 \\
\hline $\mathbf{9 . 5 8 0}$ & 0.000 & 0.016 & 0.929 \\
\hline
\end{tabular}

Figure 2 shows the crack distribution for the reinforced wall. The damage configuration appears very similar with the un

Regarding operational modal The estimated natural frequencies and are represented in Figure 5 The an in-plane mode. As in the unreinforced case,
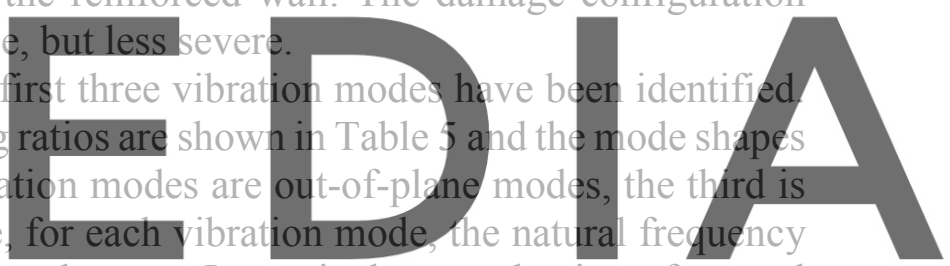
decrease and the damping ratio increase due to damage. In particular, a reduction of natural

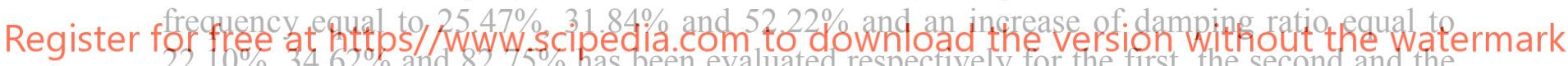
$22.10 \%, 34.62 \%$ and $82.45 \%$ has been evaluated respectively for the first, the second and the

third mode. The MAC values are reported in Table 6.

As in the unreinforced case, the results suggest that the mode shape of the second vibration mode was the most affected by the damage and that the third mode (in-plane mode) shows the greatest reduction of modal stiffness.

Table 5: Estimated natural frequencies and damping ratio for reinforced pre/post-damage wall.

\begin{tabular}{cccc}
\hline \multicolumn{2}{c}{ Pre-damage } & \multicolumn{2}{c}{ Post-damage } \\
\hline Frequency $(\mathrm{Hz})$ & Damping $(\%)$ & Frequency $(\mathrm{Hz})$ & Damping $(\%)$ \\
\hline 6.992 & 2.339 & 5.211 & 2.856 \\
\hline 16.475 & 1.473 & 11.230 & 1.983 \\
\hline 29.823 & 0.684 & 14.250 & 1.250 \\
\hline
\end{tabular}




\section{$6.992 \mathrm{~Hz}$}

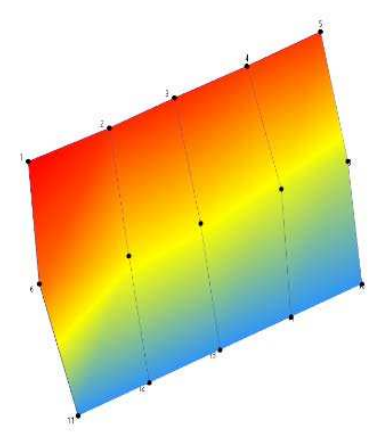

(a)
$16.475 \mathrm{~Hz}$

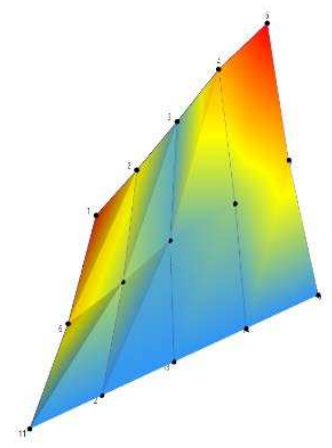

(b)
$29.823 \mathrm{~Hz}$

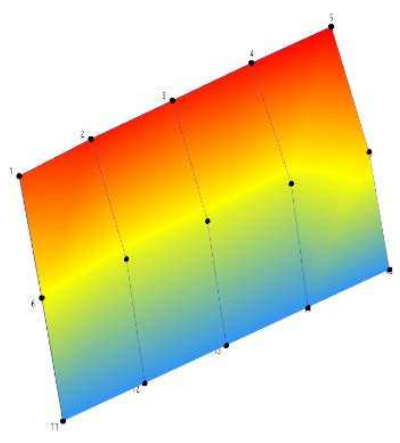

(c)

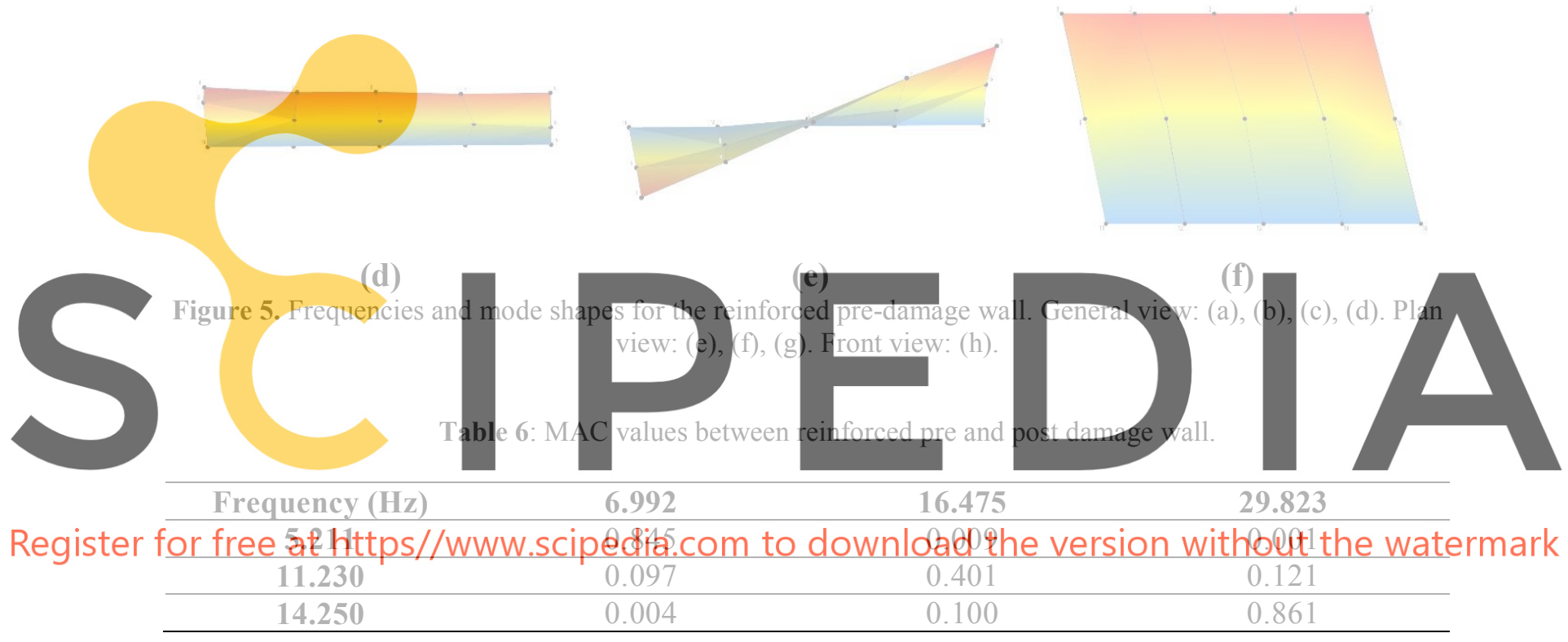

\section{CONCLUSIONS}

The dynamic behavior of a brick masonry wall before and after reinforcing with TRM was assessed. After the cyclic loads, the damping factor, the modal shapes and the vibration frequency have been evaluated. The following conclusions may be drawn for unreinforced and reinforced masonry building due to the cracking process: Reduction of vibration frequencies by $20-30 \%$, increase of the damping factor by more than $100 \%$. However no significant changes in the modal shapes have been evaluated for the first vibration modes. Regarding the effect of the TRM, the most important conclusions are related with the possibility of recovering the predamage stiffness of the building, and the negative effect in the damping factor due to the elastic behavior of these materials. 
Acknowledgements. The authors want to acknowledge Spanish Ministry of Universities for the funding provided through Projects RTI2018-101148-B-100 and BIA2015-69952-R, and also the Grupo Mapei and the Grupo Puma for their invaluable assistance.

\section{REFERENCES}

[1] Magenes, G., Calvi, G.M. In-plane seismic response of brick masonry walls, Earthq. Eng. Struct. Dyn. 26 (1996) 1091-1112.

[2] Bhattacharya, S., Nayak, S., Dutta, S.C. A critical review of retrofitting methods for unreinforced masonry structures, Int. J. Disaster Risk Reduct. 7 (2014) 51-67. doi:10.1016/j.ijdrr.2013.12.004.

[3] Triantafillou, T.C., Strengthening of masonry structures using epoxy-bonded FRP laminates, J. Compos. Constr. 2 (1998) 96-104. doi:10.1061/(ASCE)10900268(1998)2:2(96).

[4] Bilotta, A., Ceroni, F., Lignola, G.P., Prota, A., Use of DIC technique for investigating the behavior of FRCM materials for strengthening masonry elements, Compos. Part B Eng. 129 (2017) 251-270. doi:10.1016/j.compositesb.2017.05.075

[5] Bru, D., Baeza, F. J., Varona, B., Garcia-Barba, J., Ivorra, S., Static and dynamic properties

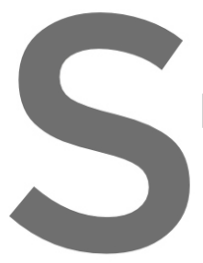
of retrofitted timb 49(1-2) 181-191.

[6] structures with $\mathrm{t}$ 188:1221-1233. Finite element an
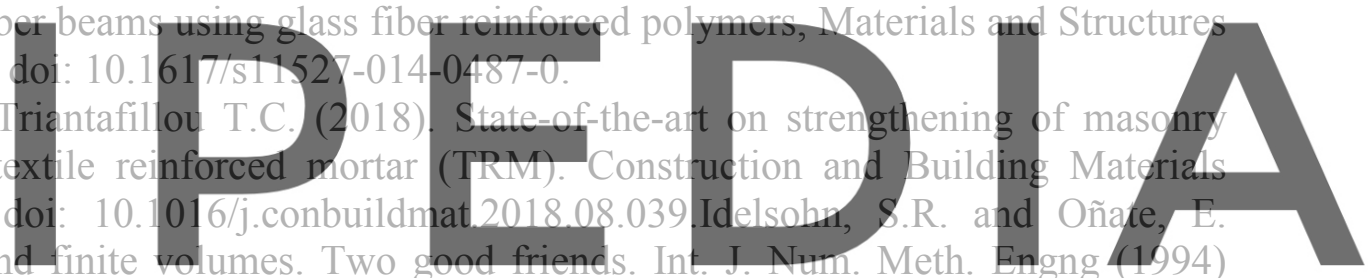
$37: 3323-3341$

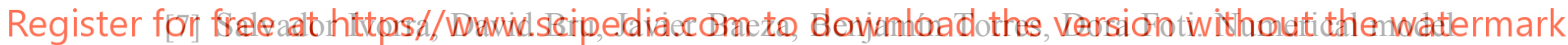
of TRM reinforced masonry walls under lateral in plane loads. 12th International Conference on Earthquake Resistant Engineering Structures ERES 2019. 5th June 2019, Seville, Spain.

[8] Juan I. Gisbert, David Bru, Antonio González, Salvador Ivorra. Masonry Micromodels Using high order 3D elements CINPAR 2018. XIV International Conference on Building Pathology and Constructions Repair. Florencia (Italy), 2018.

[9] David Bru, Salvador Ivorra, Manuel Buitrago, Elisa Bertolesi, OMA identification on a scaled masonry building pre and post reinforced with TRM. 8th International Operational Modal Analysis Conference. Copenhagen May 2019 